\title{
SUBSTITUIÇÃO DAS CHAPAS DE INOX DO FORNO DE GALVANIZAÇÃO DA CSN PORTO REAL UTILIZANDO A TÉCNICA DE ALPINISMO INDUSTRIAL*
}

\author{
Luís Claudio Antunes Ferreira ${ }^{1}$ \\ Jodalby Jose de Souza ${ }^{2}$ \\ Pedro Vitor da Silva ${ }^{3}$ \\ Renato Aguiar da Silva ${ }^{4}$
}

\begin{abstract}
Resumo
No atual cenário econômico as siderúrgicas estão buscando cada vez mais a redução dos seus custos para a produção do aço, com o objetivo de manter-se competitiva neste mercado. O custo da manutenção refratária corresponde a um valor expressivo para a produção do aço, portanto trabalhos com objetivos de novas técnicas de manutenção para aumentar a produtividade, fazem com que estes custos sejam reduzidos. A CSN Porto Real é uma filial com vocação para o mercado automobilístico e possui um forno de galvanização. Conforme o plano de manuteção houve a necessidade de troca de todas as chapas de inox do forno da linha de galvanização, pois encontravam-se queimadas e com alto grau de deformação. Esta atividade, por motivo de histórico de execução em um forno vertical, sempre foi realizada com a utilização de um grande volume de andaime e de mão de obra, tendo assim um alto custo para a sua execução. Este trabalho foi fruto do estudo para redução do custo de manutenção com a aplicação da técnica de Alpinismo Industrial para se aumentar a produtividade.
\end{abstract}

Palavras-chave: Alpinismo industrial; Fibra cerâmica; Galvanização; Produtividade.

\section{REPLACEMENT OF THE STAINLESS PLATES FROM CSN'S PORTO REAL GALVANIZATION OVEN USING THE TECHNIQUE OF INDUSTRIAL ALPINISM}

\section{Abstract}

In the current economic scenario steelmakers are seeking increasingly to reduce their costs for the production of steel, in order to remain competitive in this market. The cost of refractory maintenance corresponds to a significant value for the production of steel, so maintenance with new techniques to increase productivity and reduce equipment downtime of make these costs are reduced. CSN Porto Real is a branch with vocation for the automotive market, through its galvanizing line. According to the maintenance plan, there was the need of changing all the stainless plates from the galvanizing line oven, because they were burned and with a high degree of deformation. This activity, by reason of the execution history in a vertical oven, has always been carried out using of a large volume of scaffold and labor, driving to a high cost for its implementation. This work shows the reduction of the maintenance costs with the implementation of Industrial alpinism seeking for productivity raising.

Keywords: Industrial alpinism; Ceramic fibre; Galvanization; Productivity.

1 Técnico de Desenvolvimento, Gerência de Refratários da Companhia Siderúrgica Nacional.

Supervisor de Manutenção, Gerência de Refratários da Companhia Siderúrgica Nacional.

Técnico de Manutenção, Gerência de Refratários da Companhia Siderúrgica Nacional.

Engenheiro de Manutenção, Gerência de Refratários da Companhia Siderúrgica Nacional. 


\section{INTRODUÇÃO}

Na siderurgia, o refratário tem uma função importante para a produção do aço, onde ele está diretamente ligado a disponibilidade de seus fornos para a carteira de encomendas de produtos de aço. No atual cenário econômico as empresas siderúrgicas estão buscando, cada vez mais, a redução de seus custos de modo a se tornar uma empresa competitiva no mercado globalizado.

A CSN Porto Real é uma filial com vocação para o mercado automobilístico, localizada próximo aos maiores centros produtivos do país. A unidade tem como uma de suas características, a prestação de serviços de entregas just-in-time. A alta qualidade de suas instalações automatizadas permite que seja competitiva nos mercados nacional e internacional, disponibilizando produtos de alta qualidade para peças expostas e internas. Possui uma Linha de Galvanização Contínua de Mergulho a Quente, que realiza o processo de recozimento de recristalização e reveste a tira laminada a frio, com zinco puro em ambos os lados, seja com espessuras de camadas iguais ou diferentes.

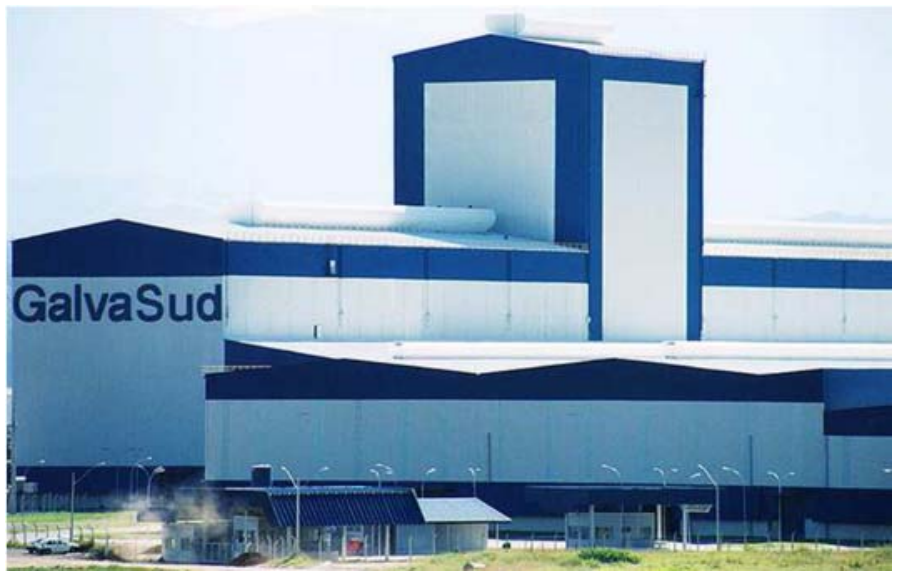

Figura 1- Linha de Galvanização da CSN Porto Real

Com um potencial de produção de 350.000 t/a, a CSN Porto Real atende a indústria automobilística, Linha Branca e outros mercados do gênero, produzindo bobina zincada, bobina Galvanneal, Blanks soldados e configurados.

\section{Produção: 350.000 t/a}

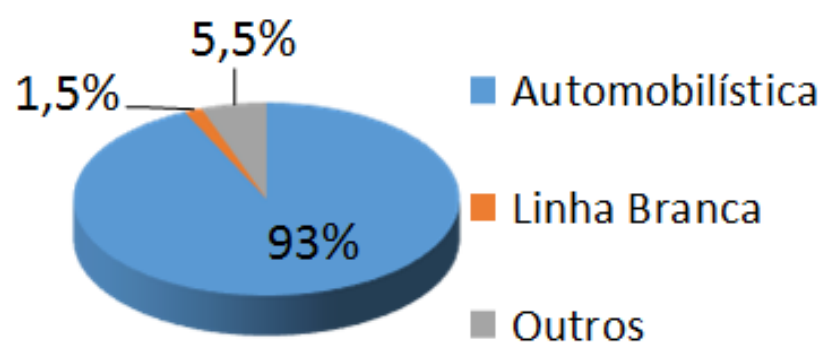

Figura 2- Produção da Linha de Galvanização

A CSN Porto Real possui um forno de recozimento que é revestido por 8 (oito) camadas de fibra cerâmica de $25 \mathrm{~mm}$ com densidade de $96 \mathrm{Kg} / \mathrm{m}^{3}$ e, mais 2 camadas de $25 \mathrm{~mm}$ com densidade de $128 \mathrm{Kg} / \mathrm{m}^{3}$. Como proteção mecânica deste revestimento de fibras temos a chapa de inox AISI309 de 0,5 mm de espessura em 
grande parte do forno. A figura $\mathrm{n}^{\circ} 3$ mostra o perfil do projeto do forno da linha de galvanização com as respectivas seções e a figura $n^{\circ} 40$ revestimento de fibra cerâmica.

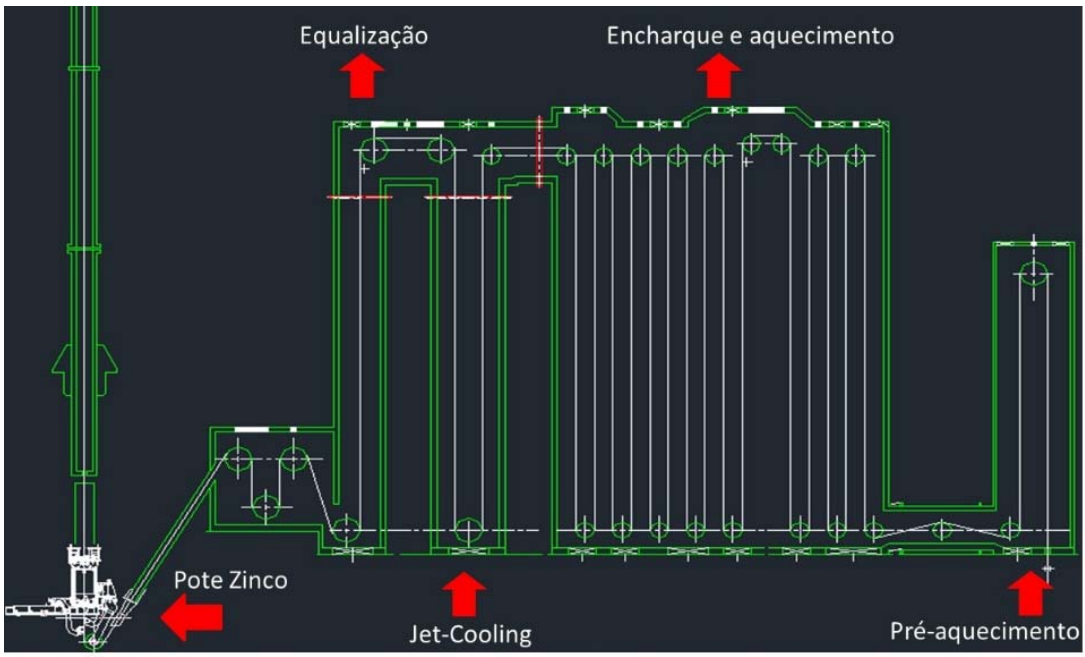

Figura 3- Perfil do forno da linha de galvanização

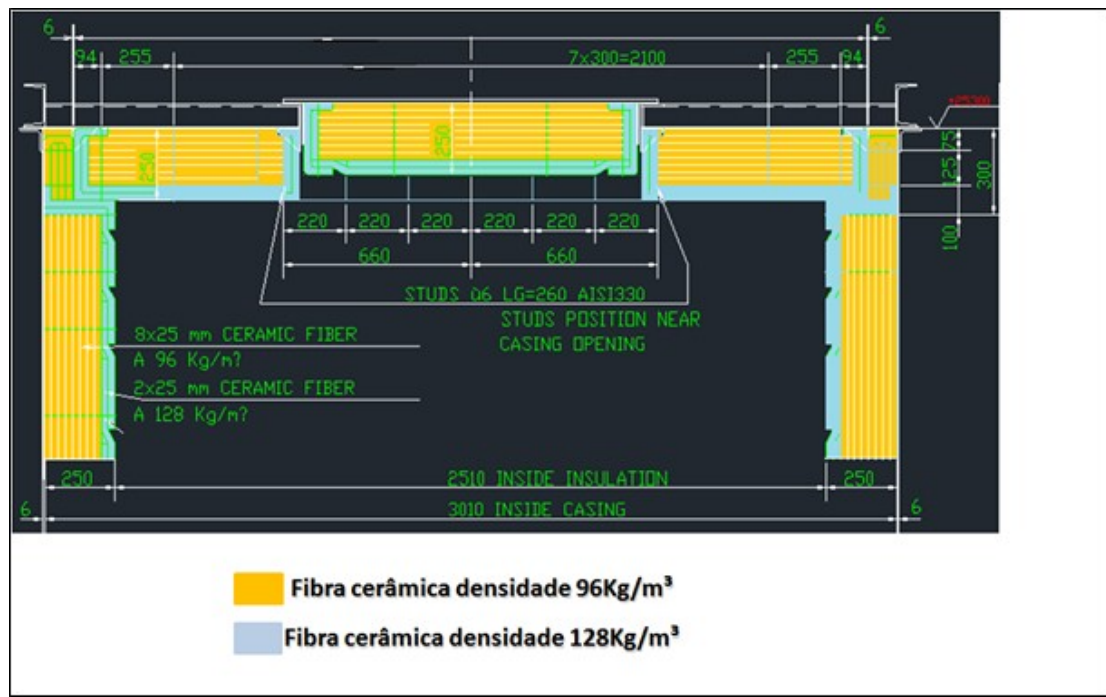

Figura 4- Projeto do revestimento do forno

\section{MATERIAIS E MÉTODOS}

\subsection{HISTÓRICO}

No ano de 2009, a Gerência de Refratários da UPV (planta de Volta Redonda) assumiu a responsabilidade pela manutenção refratária da planta da CSN Porto Real. Após a elaboração do plano de manutenção e início das inspeções internas foi verificado que as chapas de inox do forno já estavam com um grande desgaste. Estes desgastes poderiam provocar perdas de produção em função de quedas de chapa. Devido a deformação das chapas existia o risco de perda de qualidade por arranhões, devido estarem próximo do caminho da tira. A figura $n^{\circ} 5$, mostra uma perda de produção em função deste desgaste. 
ENTREGA GEF: DISPONIBILIDADE DA GGOP

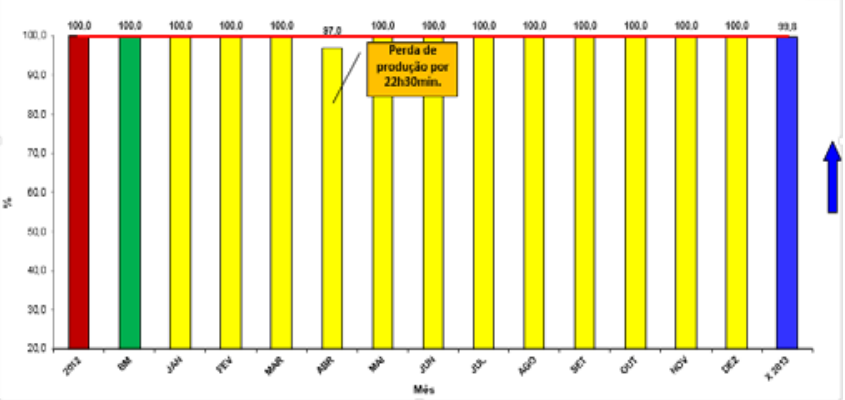

Figura 5- Gestão da disponibilidade do forno

Em uma das oportunidades de inspeção, foi mapeada a região superior do forno em função do maior volume de chapas com desgaste e perda do sistema de fixação em alguns pontos. A fixação (sistema de ancoragem) das chapas é feita por pinos soldados à carcaça e clipes de travamento, conforme figura $n^{\circ} 6$
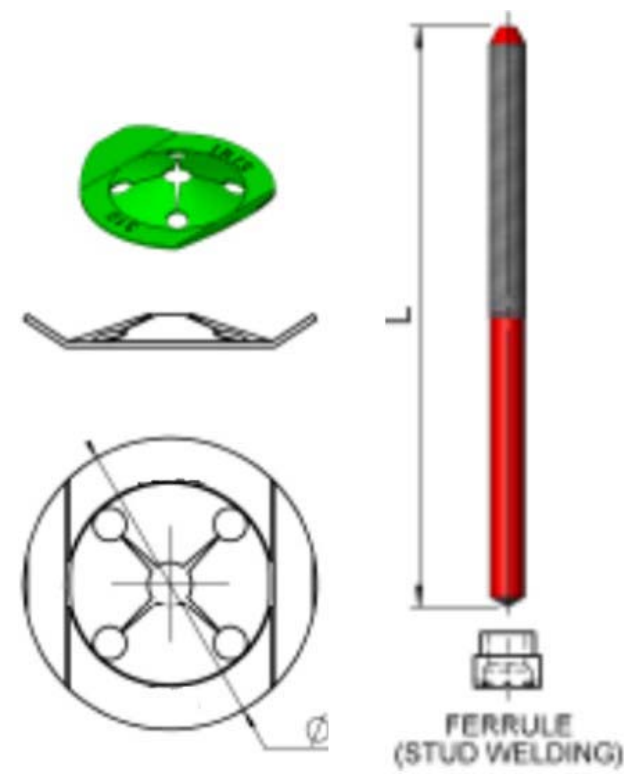

Figura 6- Sistema de ancoragem do revestimento de fibra cerâmica e chapa de inox

No ano de 2012, iniciamos o planejamento e execução de reparos localizados. Com a condição do revestimento do teto ser a região mais crítica, pois fica localizada sobre o caminho da tira, rolos superiores e inferiores, foi priorizado no início da execução do plano de manutenção. Este planejamento seria feito em etapas devido ao tempo de cada parada do forno ser de 96 horas. A figura $\mathrm{n}^{\circ} 7$ mostra o desgaste da região superior do forno entre teto e paredes. 

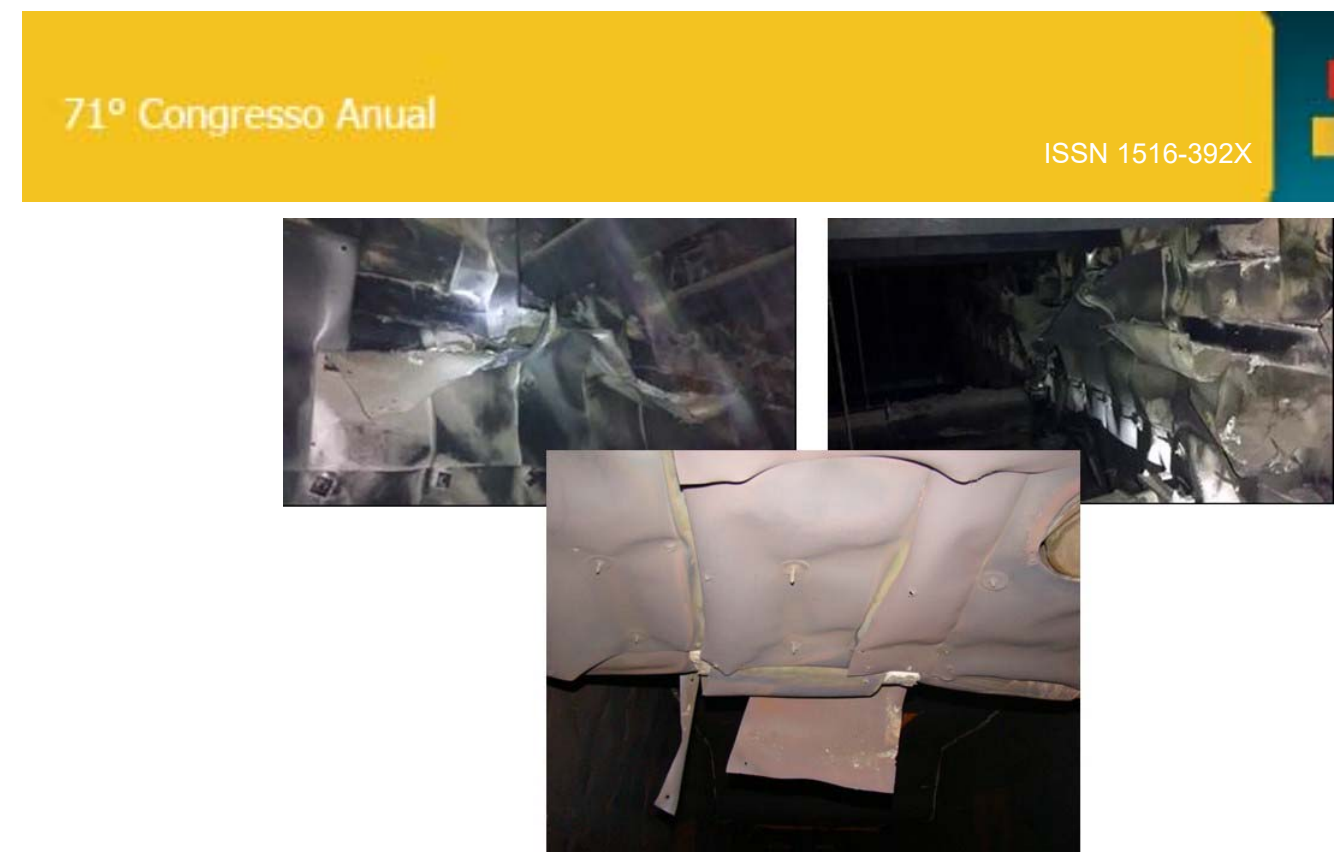

Figura 7- Chapas de inox da parede e teto com desgaste

No período de 2012 a 2013, foram realizados 3 reparos parciais na parte superior do forno, conforme Figura $n^{\circ}$ 8. O mapeamento destaca cada etapa (escopo) desta manutenção. Para os reparos de agosto de 2012 e julho de 2013, a modalidade contratada foi com a montagem de andaime para a execução das atividades.

O evento de abril de 2013 foi onde se iniciou a proposta de se realizar esta manutenção através do Alpinismo Industrial, mas sem sucesso devido a capacitação da empresa contratada neste tipo de atividade em forno vertical.

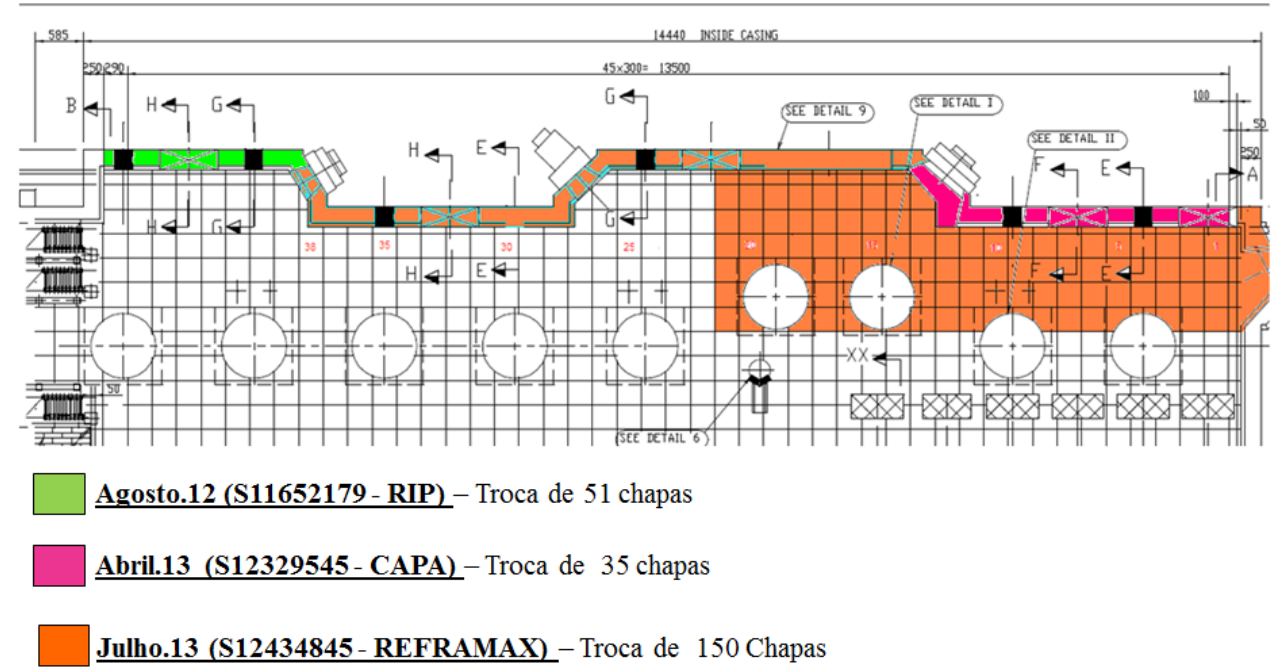

Figura 8- Mapeamento dos reparos localizados

\subsection{PLANEJAMENTO}

Em função do forno vertical, os custos de manutenção com serviços e materiais sempre foi bastante representativo e com baixo desempenho, devido à altura do forno e não haver possibilidade de se executar atividades sobrepostas, sem uma proteção física entre as frentes de serviço. A Figura $n^{\circ} 9$ mostra os custos dos eventos realizados em função do escopo realizado, baseado no valor do contrato e a quantidade de chapas substituídas, chegando a um valor de $\mathrm{R} \$ 2.205,00 /$ chapa, devido necessidade de um efetivo maior para cumprir o escopo no tempo programado. A chapa tem as dimensões de $375 \mathrm{~mm} \times 666 \mathrm{~mm}$. 

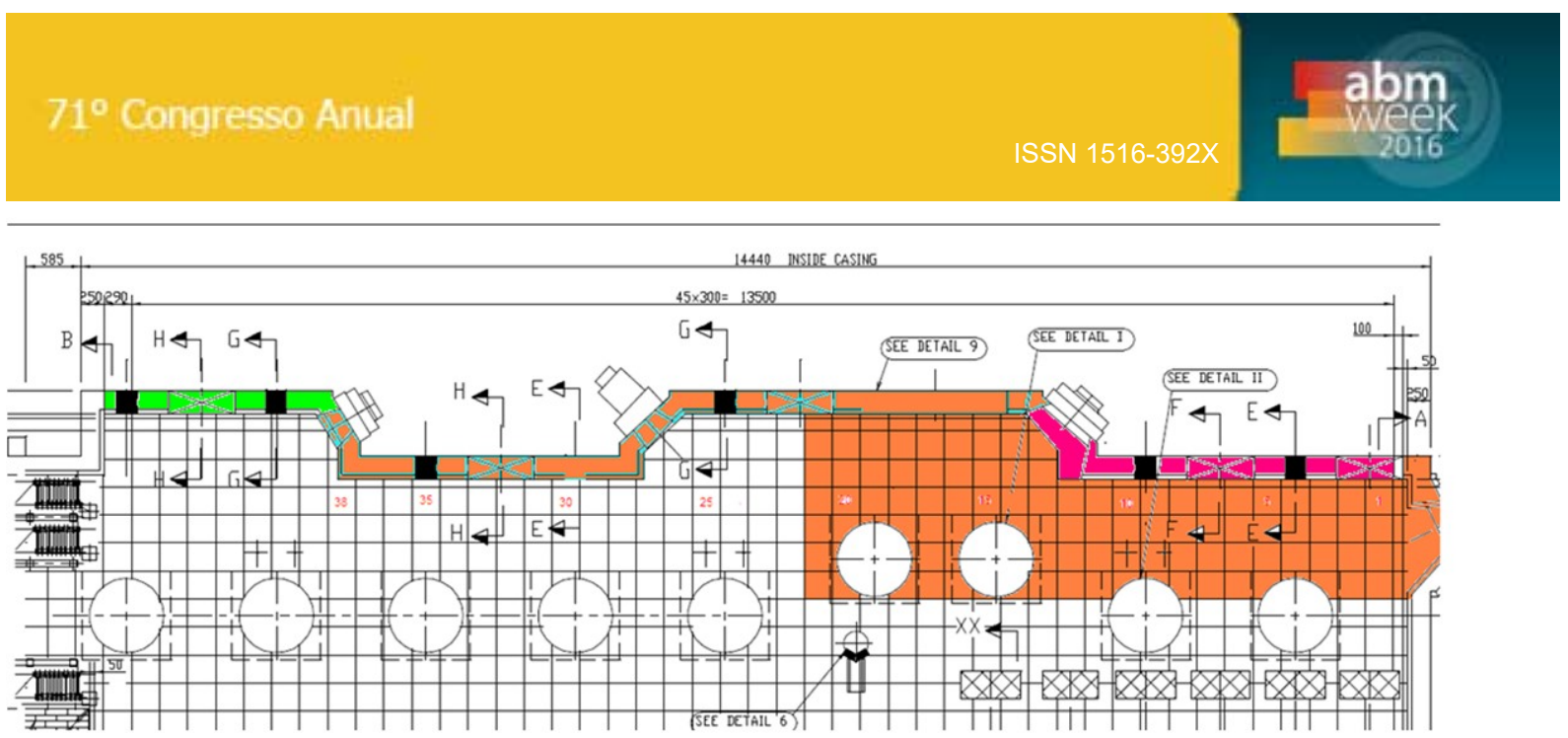

Agosto.12 (S11652179) - Troca de 51 chapas com custo de R\$ 112.486,67 ( R\$ 2.205,00/chapa) Produtividade - 14 colaboradores ( 3,6 chapas/colaborador $\mathbf{~ m ~} \mathbf{4 8 h}$ )

Abril.13 (S12329545) - Troca de 35 chapas com custo de R $\$ 6.429,02$, após multas (R\$ 183,00/chapa) Produtividade - 16 colaboradores (2,1 chapas/colaborador $\mathbf{e m} 3 \mathbf{3 h}$ )

Julho.13(S12434845) - Troca de 150 Chapas com custo de $R \$ 175.000,00$ (R\$ 1.166,00/chapa) Produtividade - 75 colaboradores ( 2 chapas/colaborador em 48h)

Figura 9- Custo e produtividade por evento de manutenção

No $3^{\circ}$ trimestre de 2014 , definiu-se em se realizar uma reforma geral no forno devido ao grande volume de chapas com desgaste. $O$ trabalho em etapas não estava sendo eficaz, pois a quantidade de chapas substituídas era pequena em relação a quantidade total do forno. Esta decisão foi visando uma recuperação do forno em um menor tempo e reduzir o custo de manutenção com um volume maior do escopo.

Em outubro de 2014 foi realizada uma inspeção, conforme Figura 10 para definição deste escopo em uma parada programada de 15 dias de bobina a bobina. A Figuras $\mathrm{n}^{\circ} 11$ mostra uma das regiões inferiores e superiores do interior do forno com um grande desgaste e risco de parada de processo por problemas de qualidade. $\mathrm{Na}$ realidade todo o forno necessitava de substituição das chapas de inox. Neste planejamento, definiu-se que o reparo geral seria composto pelas regiões da seção de aquecimento e encharque, teto do túnel e teto do jet cooling, conforme foto $n^{\circ} 12$.

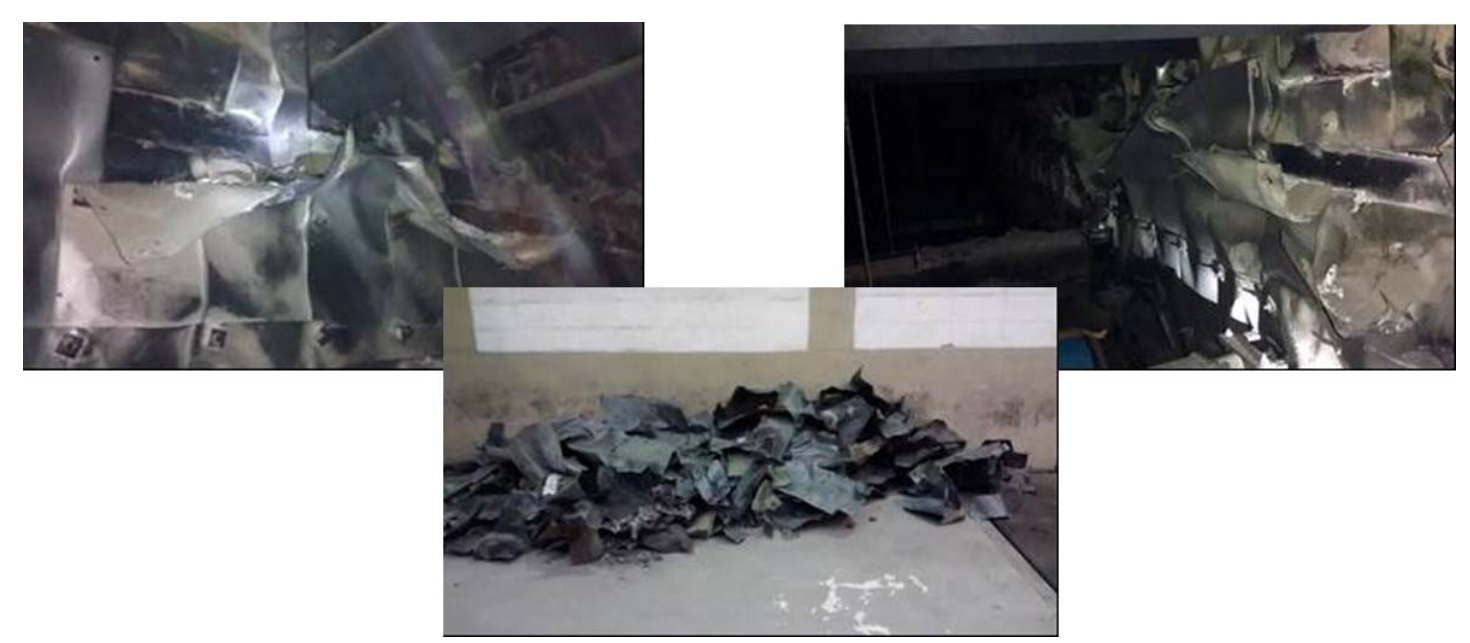

Figura 10- Inspeção realizada em outubro de 2014 

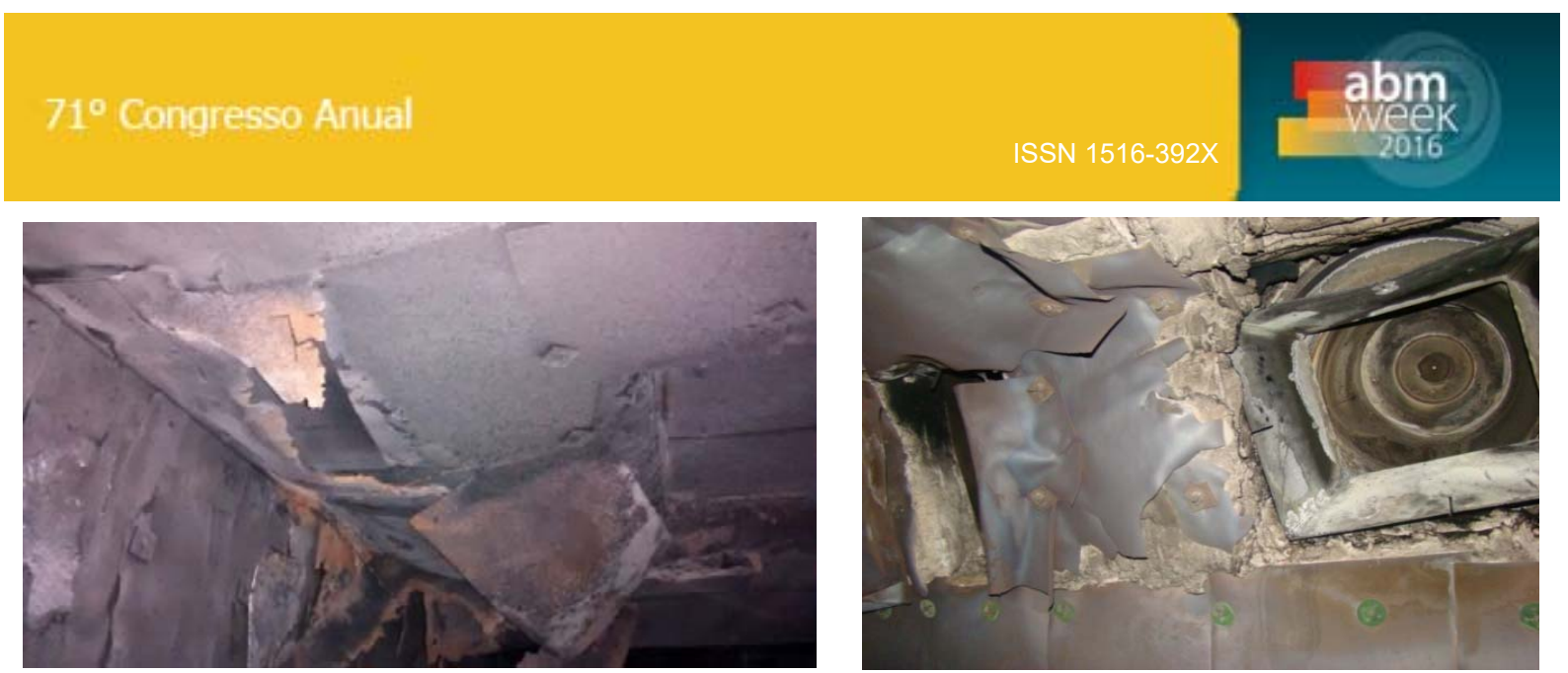

Figura 11- Chapa do teto do túnel na região inferior e superior do forno

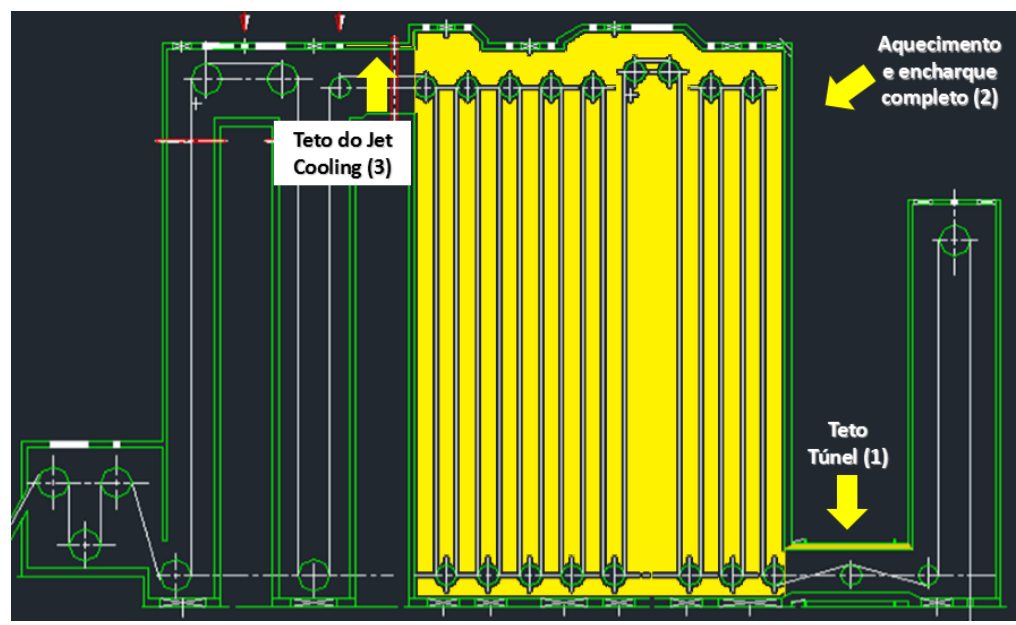

Figura 12- Mapeamento do escopo

A memória de cálculo da tabela $\mathrm{n}^{\circ} 1$, foi nossa referência para definição do orçamento do escopo do reparo geral. Este cálculo teve como referência os reparos localizados anteriores. Esta memória mostrou um orçamento previsto de $\mathrm{R} \$$ 1.197.052,00, nossa requisição de serviço foi inserida no sistema com o valor de $R \$$ 1.100.000,00. Em função da redução de carteira, decorrente da crise que já vinha restringindo o mercado do aço, o orçamento para este evento disponibilizado pelo gestor da área foi de $\mathrm{R} \$ 470.000,00$. Mesmo com esta grande diferença iniciamos o processo de concorrência com objetivo de alcançar o menor orçamento de serviços e chegar próximo ao que foi disponibilizado pelo gestor do equipamento.

\begin{tabular}{|c|c|c|c|c|c|}
\hline \multicolumn{6}{|c|}{ MEMÓRIA DE CÁLCULO } \\
\hline \multirow{2}{*}{\multicolumn{4}{|c|}{ Referência: }} & Área $\left(\mathrm{m}^{2}\right)$ & Valor (R\$) \\
\hline & & & & 716 & $1.100 .000,00$ \\
\hline & Altura & Largura & Área $\left(\mathrm{m}^{2}\right) \mid$ & Valor Região & $\begin{array}{c}\text { Valor cada } \\
\text { parede }\end{array}$ \\
\hline Paredes do Aquecimento & 21,53 & 11 & 473,70 & $727.757,54$ & $363.878,77$ \\
\hline Paredes do Encharque & 21,53 & 3,44 & 148,14 & $227.589,63$ & $113.794,82$ \\
\hline Parede entrada aqueciment & 19,15 & 2,51 & 48,06 & $73.829,76$ & \\
\hline Parede saída encharque & 18,51 & 2,51 & 46,45 & $71.361,82$ & \\
\hline Teto aquecimento/encharq & 14,44 & 2,51 & 36,24 & $55.682,74$ & \\
\hline \begin{tabular}{|l|l} 
Teto do túnel \\
\end{tabular} & 4,5 & 2,71 & 12,20 & $18.735,34$ & \\
\hline Teto do Jet Cooling & 3,6 & 2,51 & 9,04 & $13.882,12$ & \\
\hline 5 tampas superiores & 1,32 & 0,81 & 1,07 & $8.213,13$ & \\
\hline Total RC & & & 774,90 & $1.197 .052,08$ & \\
\hline
\end{tabular}

Tabela 1- Levantamento das trocas de chapa de inox em reparos anteriores 


\subsection{ANÁLISE DAS PROPOSTAS}

Após a $1^{\text {a }}$ visita técnica, algumas empresas apresentaram cronograma e organogramas muito diferentes em relação ao escopo CSN. A Tabela $\mathrm{N}^{\circ} 2$ mostra este planejamento das concorrentes com a utilização de andaime para a realização dos serviços. O valor médio obtido ficou próximo a memória de cálculo e bem acima do valor orçado.

\begin{tabular}{|l|c|c|}
\hline \multicolumn{1}{|c|}{ EMPRESA } & EFETIVO & CRONOGRAMA \\
\hline RIP & 106 & 15 DIAS \\
\hline REFRAMAX & 95 & 15 DIAS \\
\hline DSI & 110 & 41 DIAS \\
\hline MAGNESITA & 66 & 32 DIAS \\
\hline LAMCAP & 64 & 30 DIAS \\
\hline
\end{tabular}

Tabela 2- Efetivo e tempo das empresas concorrentes

Em decorrência do valor médio das propostas ter finalizado em $R \$ 1.276 .500,00$, conforme comunicado da área comercial (figura $\mathrm{n}^{\circ} 13$ ), foi definido realizar mais uma etapa de visita técnica com outras empresas com objetivo de reduzir o custo de contratação.

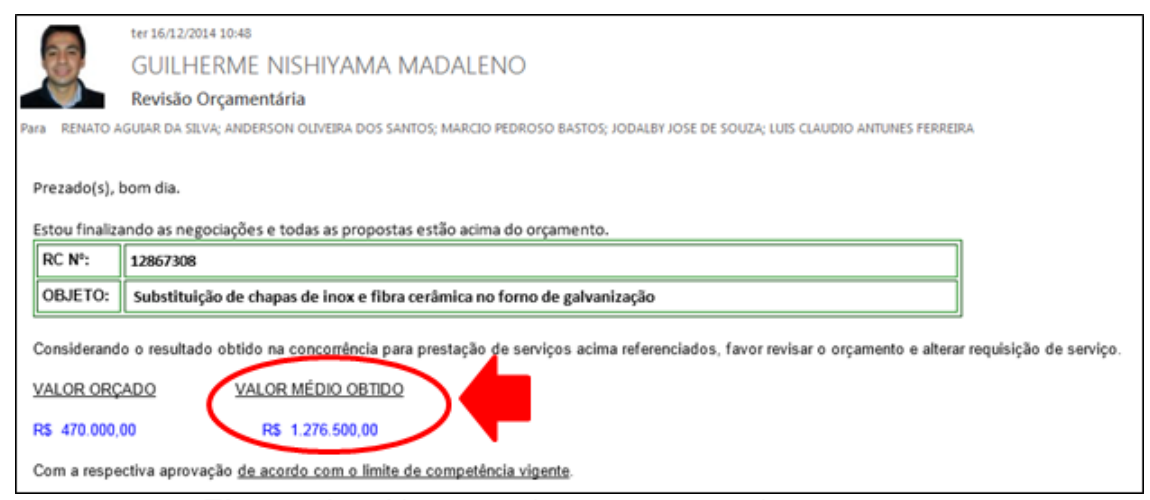

Figura 13- Abertura das propostas desta $1^{\text {a }}$ etapa

A $2^{\mathrm{a}}$ etapa foi composta por mais 03 visitas técnicas entre os dias 19/12/14 a 07/01/15, também, com o escopo básico de andaime para a realização dos serviços. Após a abertura e negociação, o valor médio obtido foi na ordem de $\mathrm{R} \$$ $1.000 .000,00$ (figura $n^{\circ} 14$ ), mostrando que o objetivo de reduzir o custo de contratação estava sendo eficaz, pois a redução do custo de contratação já estava próxima de $22 \%$ abaixo da $1^{\text {a }}$ etapa. 
GUILHERME NISHIYAMA MADALENO

RES: URGENTE - Concorrência 14.12867308 - Substituição de Chapas Para JODALBY JOSE DE SOUZA

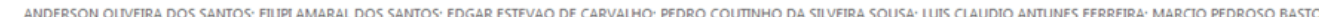

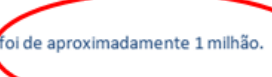

Figura 14- Abertura das propostas desta $2^{\mathrm{a}}$ etapa

Definiu-se continuar, e foram realizadas mais 3 visitas técnicas no período de 05/02/15 a 13/02/2015. Em uma destas visitas, fizemos a opção de retornar com a modalidade de alpinismo industrial, para conhecer melhor seu planejamento, estrutura e organograma em relação ao modelo tradicional com andaime. Na visita técnica do dia 10/02/2015 das empresas convidadas para participar na modalidade de alpinismo, a única que compareceu foi a CMI. Nesta visita além da apresentação do escopo, a CMI apresentou a forma de trabalho sem andaime e com referências de escopos semelhantes, organogramas adotados, instruções de segurança e acompanhamento de saúde ocupacional de seus colaboradores.

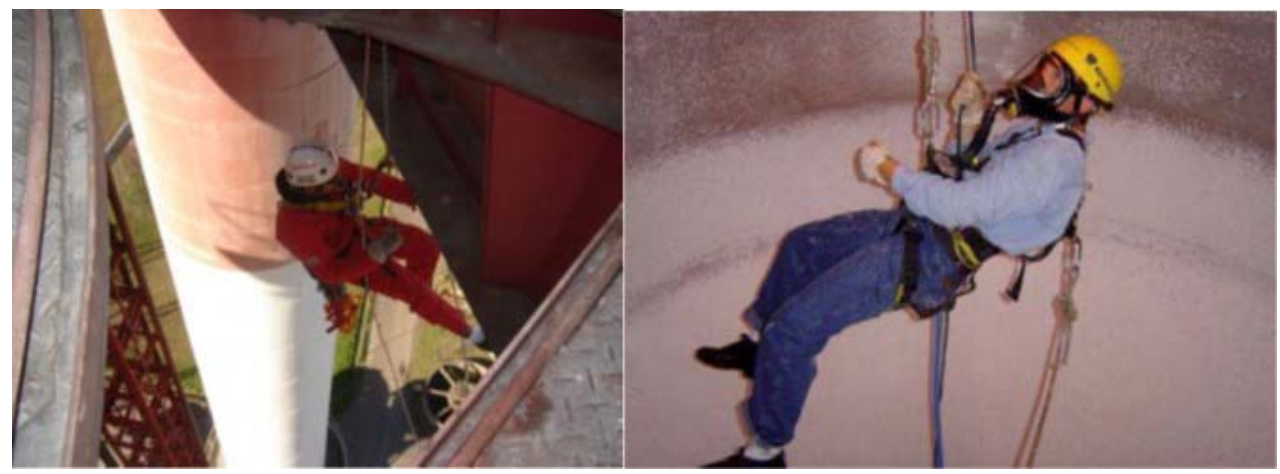

Figura 15- Alpinismo industrial para atividades em áreas verticais

Após a abertura e negociação desta etapa, fomos comunicados pela área comercial que o valor médio obtido ficou na ordem de $R \$ 580.000,00$ (figura $n^{\circ} 16$ ), ou seja, bem próximo dos $R \$ 470.000,00$ disponibilizados para o reparo, e ainda com baixo efetivo e tempo de reparo dentro do programa disponibilizado pela CSN Porto Real.

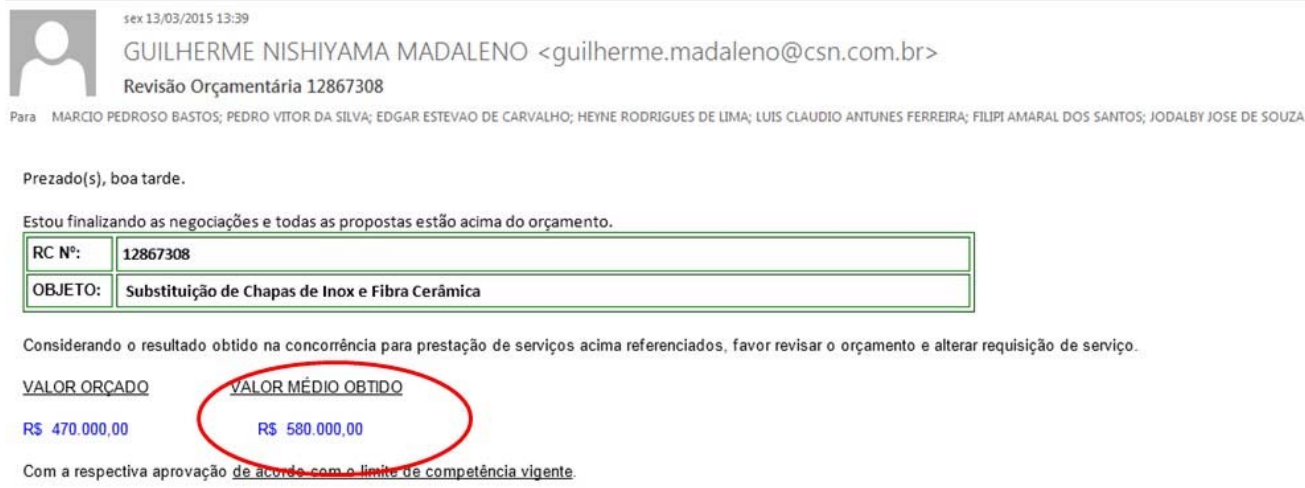

Figura 16- Abertura das propostas desta $3^{\mathrm{a}}$ etapa 


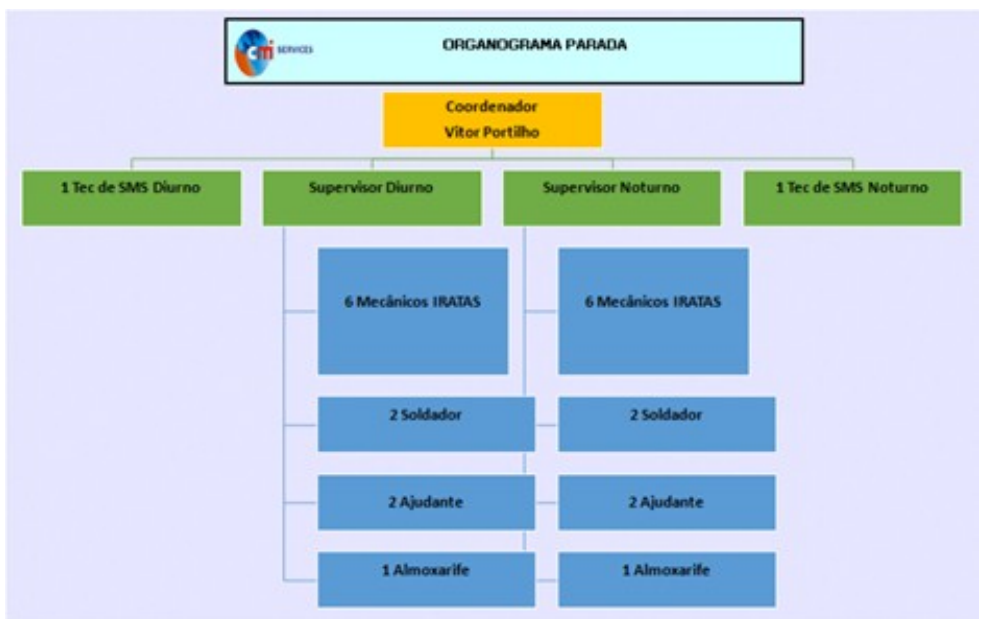

Figura 17- Organograma da melhor proposta - 22 Colaboradores

Em paralelo ao processo de contratação, especificamos o código para compra das chapas em forma de bobina para reduzir o custo unitário de cada chapa de projeto. Foram adquiridos 10 ton. de chapa (3 bobinas separados em lotes), conforme Figura 18

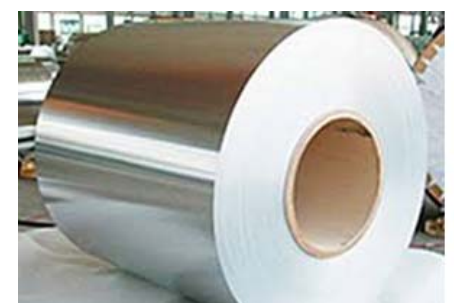

\begin{tabular}{||c|c|c|c|c|}
\hline Lote & Peso & Esp & Larg & Comp \\
\hline 1 & 3710 & 1,2 & 1539 & 255 \\
\hline 2 & 2810 & 1,2 & 1539 & 193 \\
\hline 3 & 3580 & 1,2 & 1539 & 246 \\
\hline
\end{tabular}

Figura 18- Bobina de inox e a especificação dos lotes

Conforme estratégia para a aquisição das chapas de inox, as bobinas foram cortadas no Centro de Serviços, dentro da própria planta da CSN Porto Real, conforme dimensões de projeto. Foi elaborado um Plano de Corte para reduzir ao máximo as sobras do material, conforme figura $\mathrm{n}^{\circ} 19$. Após o corte, a CMI realizou a preparação das chapas em uma usinagem próximo a cidade de Volta Redonda.

Cortar todo o lote com 1.528 chapas de $375 \times 666$ (quantidade baseada no comprimento que foi calculado) Lote 2:

- Cortar todo o lote com 1.156 chapas de $375 \times 666$ (quantidade baseada no comprimento que foi calculado) Lote 3:

Cortar 320 chapas de $375 \times 666$ (quantidade baseada no comprimento que foi calculado)

- Cortar 50 chapas de $250 \times 2.000$ (para acabamento dos cantos)

- Cortar 34 chapas de $1.539 \times 1.500$ (para acabamento dos rolos)
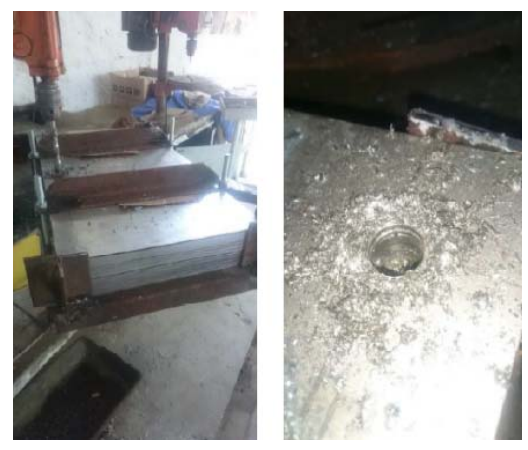

Figura 19- Plano de corte e preparação

\subsection{EXECUÇÃO DO EVENTO}

A execução de todo o escopo de serviços foi realizada através de cordas, somente na região do teto a própria empresa montou um andaime para a troca de chapas, 
sem aumentar o seu efetivo proposto. Este é a região onde o sistema de Alpinismo não consegue realizar (atividade sobre cabeça). Todo o sistema de segurança é feito por cordas certificadas, sendo uma corda de trabalho e outra de segurança, conforme figura $\mathrm{n}^{\circ} 20$

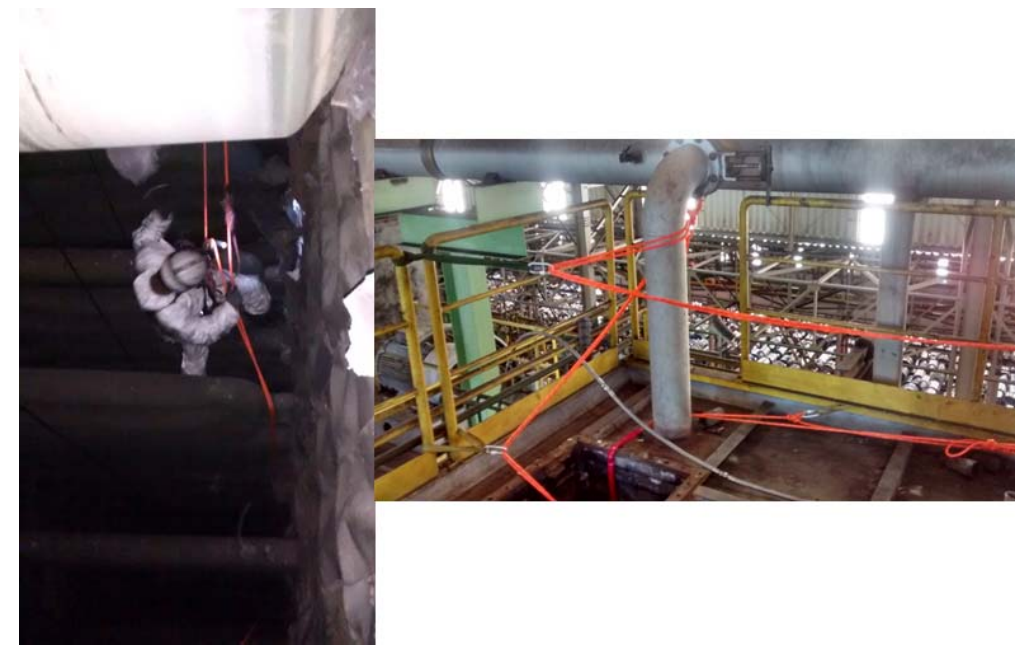

Figura 20- Sistema de acesso e segurança por cordas certificadas

A Figura $n^{\circ} 21$ mostra alguns pontos no teto e parede já com a substituição das chapas de inox. O sistema de movimentação por cordas é muito rápido dentro do forno, facilitando a execução das atividades e contribuindo muito para a segurança em função do pouco volume de pessoas e equipamentos. A Figura $n^{\circ} 22$ mostra a atividade sendo realizada com segurança dentro do forno.

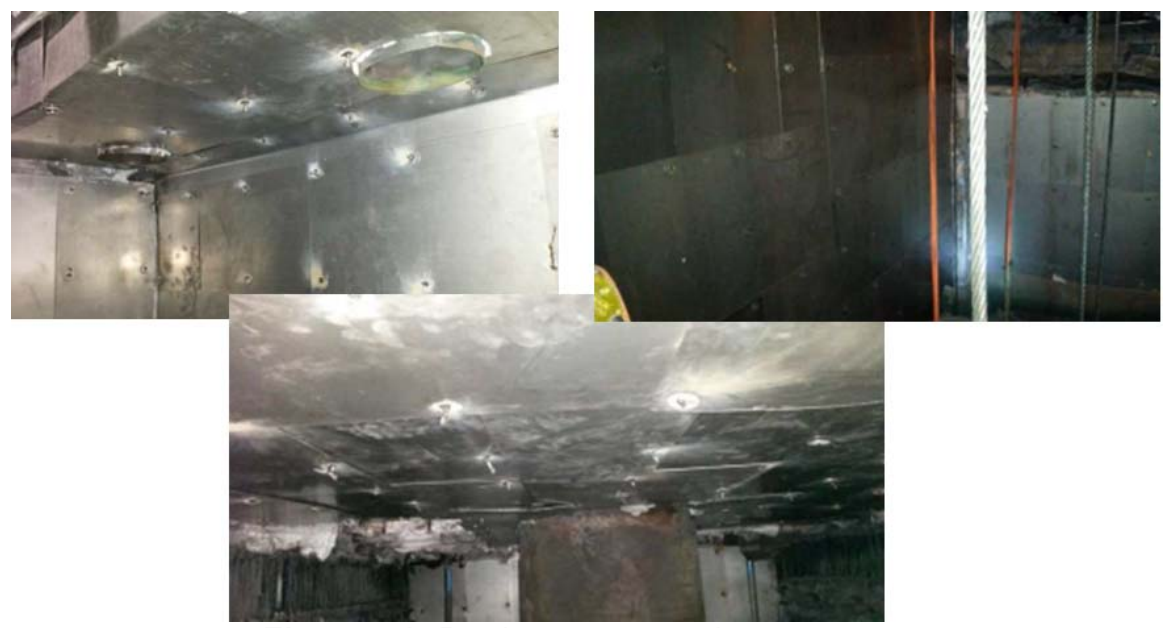

Figura 21- Regiões com as chapas novas
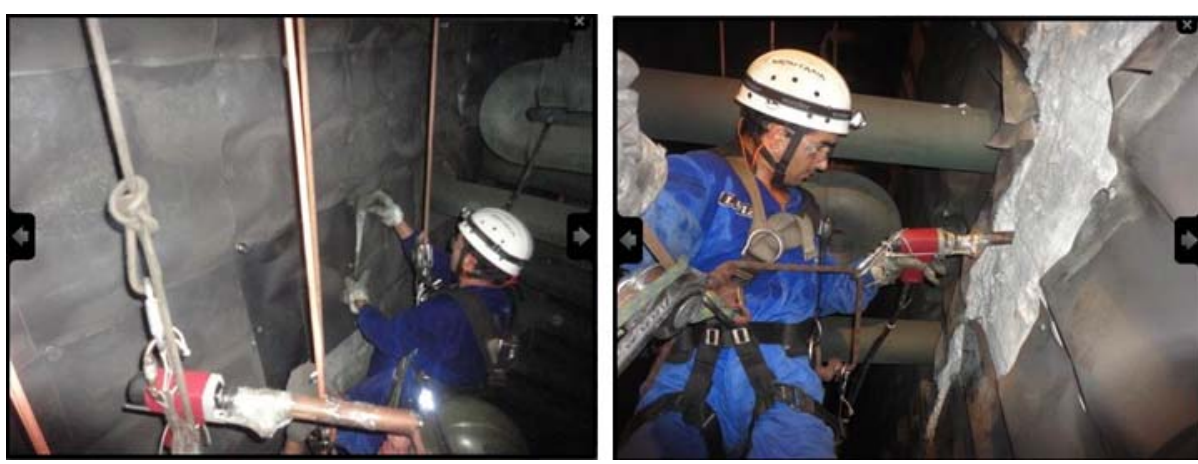

Figura 22- Alpinistas na substituição das chapas 

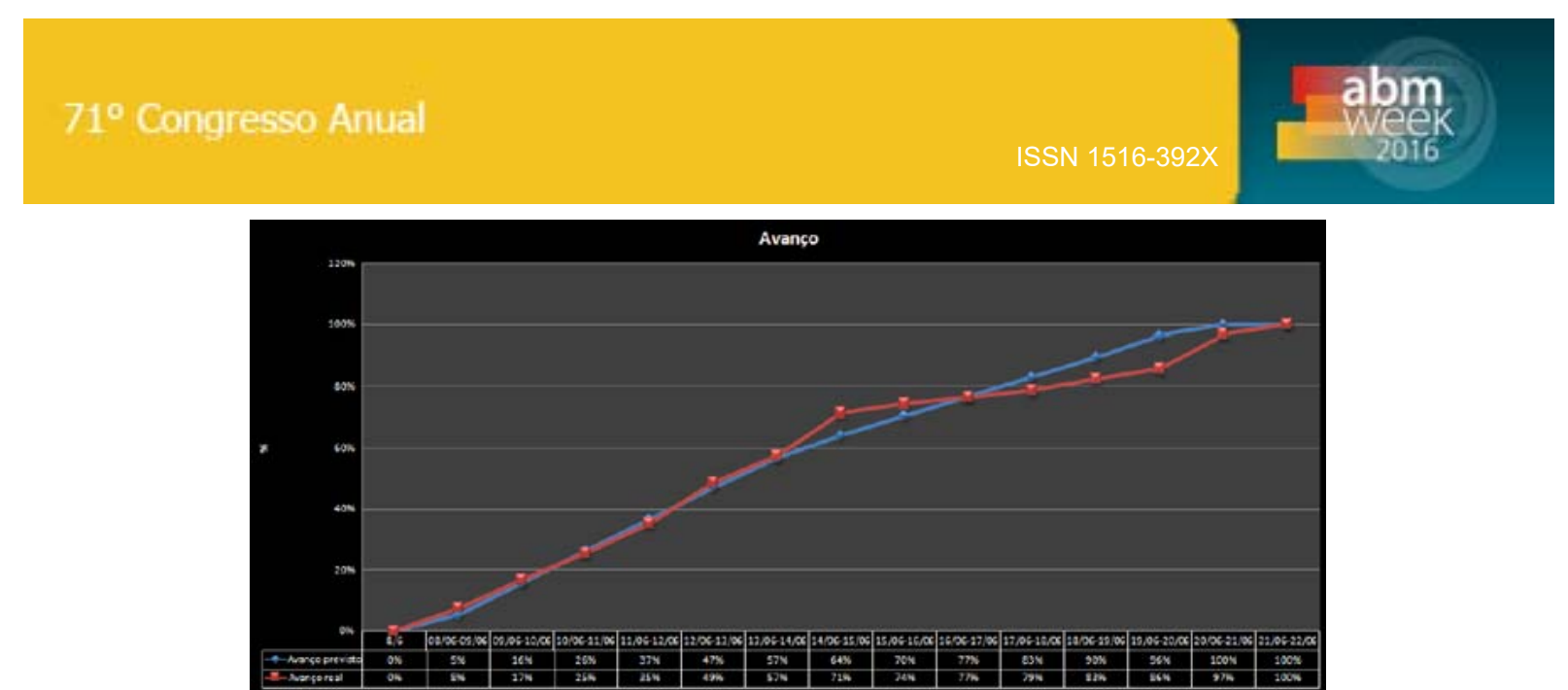

Figura 23- Gráfico de produção da montagem das chapas

\section{RESULTADOS E DISCUSSÃO}

Para os resultados obtidos com esta modalidade de execução de serviços em forno vertical, através do alpinismo industrial, podemos destacar na tabela $n^{\circ} 3$ uma produção maior na substituição das chapas de 0,076 para 0,347 chapas/colaborador. Outro fator importante foi o cumprimento do prazo de 15 dias estabelecido para a realização dos serviços. Se as atividades fossem com a utilização de andaime, a projeção de troca de chapas por colaborador seria de 27,3 chapas em $360 \mathrm{~h}$ de reparo. A redução foi de $55 \%$ no desembolso deste evento, ficando na ordem de $\mathrm{R} \$ 696.000,00$ e próximo do orçamento disponibilizado.

A não utilização de andaimes reduz em muito os riscos de acidente com pessoas e equipamentos em função do grande volume de peças que seria necessária para movimentação e montagem. Neste caso seriam necessários $750 \mathrm{~m}^{3}$ de andaime para acesso interno ao forno.

\begin{tabular}{|c|l|c|r|r|r|r|r|r|}
\hline Contrato & $\mathbf{N}^{\circ}$ contrato & Modalidade & $\begin{array}{c}\text { Quant. } \\
\text { chapas } \\
\text { substituidas }\end{array}$ & $\begin{array}{c}\text { Efetivo do } \\
\text { contrato }\end{array}$ & $\begin{array}{c}\text { Qt. de } \\
\text { chapa/colaborador }\end{array}$ & $\begin{array}{c}\text { Tempo de } \\
\text { reparo (h) }\end{array}$ & $\begin{array}{c}\text { Qt. de chapa } \\
\text { substituída/hora }\end{array}$ & $\begin{array}{c}\text { Qt. chapa subst./colaborador } \\
\text { em reparo de 360h }\end{array}$ \\
\hline $1^{\circ}$ & $\mathrm{S} 11652179$ & Andaime & 51 & 14 & 3,6 & 48 & 0,08 & \\
\hline $2^{\circ}$ & $\mathrm{S} 12329545$ & Andaime & 35 & 16 & 2,2 & 36 & 0,06 & 2,3 \\
\hline $3^{\circ}$ & $\mathrm{S} 12434845$ & Andaime & 150 & 75 & 2,0 & 48 & 0,04 & 1,9 \\
\hline $4^{\circ}$ & $\mathrm{S} 12867308$ & Alpinismo & 3.000 & 24 & $\mathbf{1 2 5 , 0}$ & 360 & 0,35 & \\
\hline
\end{tabular}

Tabela 3- Produtividade na troca de chapas

A tabela $n^{\circ} 4$ mostra que o reparo feito na modalidade de andaime teria uma projeção de prazo de 40 dias.

\begin{tabular}{|c|c|c|r|r|r|r|}
\hline Contrato & $\mathbf{N}^{\circ}$ contrato & Modalidade & $\begin{array}{c}\text { Quant. } \\
\text { chapas } \\
\text { substituidas }\end{array}$ & $\begin{array}{c}\text { Tempo de } \\
\text { reparo } \\
\text { (dias) }\end{array}$ & $\begin{array}{c}\text { Qt. de chapa } \\
\text { substituida/dia }\end{array}$ & $\begin{array}{c}\text { Qt. dias para troca } \\
\text { de 3.000 chapas }\end{array}$ \\
\hline $1^{\circ}$ & $\mathrm{S} 11652179$ & Andaime & 51 & 2 & 25,5 & 117,6 \\
\hline $2^{\circ}$ & $\mathrm{S} 12329545$ & Andaime & 35 & 1,5 & 23,3 & 128,6 \\
\hline $3^{\circ}$ & $\mathrm{S} 12434845$ & Andaime & 150 & 2 & 75,0 & $\mathbf{4 0 , 0}$ \\
\hline $4^{\circ}$ & $\mathrm{S} 12867308$ & Alpinismo & 3.000 & 15 & 200,0 & 15,0 \\
\hline
\end{tabular}

Tabela 4- Projeção de tempo de reparo (forno parado)

\section{CONCLUSÃO}

Após a realização deste reparo no forno de galvanização da CSN Porto Real, constatamos a eficiência desta modalidade de alpinismo industrial para a execução de atividades, principalmente em áreas verticais onde o acesso é difícil. A segurança na realização das atividades, que era uma de nossas preocupações, foi bem acima das expectativas em decorrência da experiência nesta atividade pela empresa, pelo 
número pequeno de pessoas executando e, também, pelo pequeno volume de equipamentos e ferramentas.

A partir deste evento, temos mais uma opção de execução de atividades que possa ser consultada com objetivo de redução de custos para as inspeções internas no forno, ensaios e medições em rolos superiores e inferiores, troca de resistência entre outros.

\section{Agradecimentos}

Para a realização deste trabalho, agradecemos a:

- Empresa CMI Brasil;

- Equipe de gestores e técnicos da CSN Porto Real;

- Equipe da Gerência de Manutenção de Refratários da CSN 